Original article

\section{The role of individual, household, and area of residence factors on self-rated health in Colombian adults: A multilevel study}

\author{
Beatriz Caicedo-Velásquez ${ }^{1,2}$, María Clara Restrepo-Méndez ${ }^{3}$ \\ ${ }^{1}$ Facultad Nacional de Salud Pública, Universidad de Antioquia, Medellín, Colombia \\ ${ }^{2}$ Grupo de Investigación Epidemiología y Bioestadística, Universidad CES, Medellín, Colombia \\ ${ }^{3}$ Oxford Maternal and Perinatal Health Institute (OMPHI), University of Oxford, Oxford, England
}

Introduction: Self-rated health is strongly associated with morbidity and mortality. It is largely influenced by individual factors but also by individuals' social surroundings and environment.

Objective: To investigate individual, household, and locality factors associated with selfrated health in Colombian adults.

Materials and methods: We conducted a cross-sectional multilevel study using data from national databases on 19 urban localities and 37,352 individuals nested within 15,788 households using a population-based survey. Given the natural hierarchical structure of the data, the estimates of self-rated health related to individual, household, and locality characteristics were obtained by fitting a three-level logistic regression.

Results: The adjusted multilevel logistic models showed that at individual level, higher odds of poor self-rated health were found among older adults, persons from low socio-economic status, those living without a partner, with no regular physical activity, and reporting morbidities. At the household level, poor self-rated health was associated with households of low socioeconomic status located near noise sources and factories and in polluted and insecure areas. At the locality level, only poverty was associated with poor self-rated health after adjusting for individual and household variables.

Conclusions: These results highlight the need for a more integrated framework when designing and implementing strategies and programs that aim to improve health conditions in urban populations in Latin America.

Received: $20 / 11 / 2018$

Accepted: 28/08/2019

Published: 04/09/2019

Citation:

Caicedo-Velásquez B, Restrepo-Méndez MC. The role of individual, household, and area of residence factors on self-rated health in Colombian adults: A multilevel study. Biomédica. 2020;40:296-308. https://doi.org/10.7705/biomedica.4818

\section{Corresponding author:}

Beatriz Caicedo-Velásquez, Facultad Nacional de Salud Pública, Universidad de Antioquia, Calle 62 No 52-59, Medellín, Colombia

Telephone: (57) (315) 6120858

beatriz.caicedo@udea.edu.co

\section{Author contributions:}

Beatriz Caicedo-Velásquez: main idea, statistical design, data analysis, and interpretation of findings María Clara Restrepo-Méndez: development work, writing of the manuscript, and interpretation of the findings

\section{Funding:}

This research project was funded by the Convocatoria de Sostenibilidad CODI 2016-2017 of Universidad de Antioquia. María Clara RestrepoMéndez was supported by the Brazilian Higher Education Research Council (Coordenação de Aperfeiçoamento de Pessoal de Nível Superior, CAPES).

Conflicts of interest:

The authors declare no conflicts of interest.
Keywords: Residence characteristics; social conditions; multilevel analysis; adult; Colombia

Efecto de las condiciones individuales, del hogar y del área de residencia en la autopercepción de su salud en adultos colombianos: un estudio multinivel

Introducción. La autopercepción de la salud se asocia con la morbilidad y la mortalidad debido principalmente al efecto de las condiciones individuales y las características sociales y del ambiente en el que viven las personas.

Objetivo. Investigar los factores individuales, del hogar y de la localidad asociados con la autopercepción de la salud en adultos colombianos.

Materiales y métodos. Se llevó a cabo un estudio transversal. La información sobre las 19 localidades urbanas consideradas se obtuvo de bases de datos nacionales, en tanto que los datos sobre los 37.352 individuos anidados en 15.788 hogares provinieron de una encuesta de base poblacional. Dada la estructura jerárquica de los datos, las estimaciones del efecto de las variables individuales, del hogar y de la localidad sobre la autopercepción de la salud se hicieron utilizando un modelo de regresión logística de tres niveles. Resultados. Los modelos multinivel ajustados evidenciaron que a nivel individual había una mayor probabilidad de tener una peor percepción de la salud entre adultos mayores, personas de bajo nivel socioeconómico, sin compañero, físicamente inactivos y con enfermedades. A nivel de hogar, la peor percepción de la salud se asoció con la pertenencia a familias de bajo nivel socioeconómico, residentes cerca de fábricas, áreas contaminadas, inseguras y de alto ruido. Por último, a nivel de localidad y después del ajuste por variables individuales y del hogar, la residencia en localidades pobres aumentó la probabilidad de tener una peor percepción de la propia salud.

Conclusiones. Los resultados evidencian la necesidad de considerar un marco conceptual más amplio en el momento de diseñar e implementar estrategias y programas que apunten al mejoramiento de las condiciones de salud de las poblaciones urbanas en Latinoamérica.

Palabras clave: características residenciales; condiciones sociales; análisis multinivel; adulto; Colombia. 
Self-rated health is an indicator of the quality of life that is related to the self-perception of an individual's health status $(1,2)$. Self-perception is a practical method for collecting information on individual health since it entails a single aspect: a subject's perception of his or her health status (1). This information is useful for planning, implementing, and monitoring health initiatives and programs as it has been found that self-rated health is strongly associated with morbidity and mortality (3-8), a relationship that remains after adjusting for physical, sociodemographic, and behavioural factors (3-8).

Self-rated health is influenced by individual factors such as sex, age, race, ethnicity, education levels, wealth, and employment status (1,9-13). Furthermore, common factors among groups of people like their social surroundings and environment play a role in the self-perception of their health (14-23).

It should be mentioned that the term contextual or neighbourhood effects involves both structural and social aspects. Structural characteristics refer to the physical and natural environment where individuals live measured through socio-demographic characteristics such as poverty, family structure, unemployment, and the availability of education, employment, transportation, health care, grocery shopping, and recreational services (24). The social characteristics refer to the social and organizational processes or collective aspects of community life that may influence residents' behaviour (19), in other words, social networks, control, cohesion, norms for support, perceptions of violence, and collective efficacy (25). Some studies that have examined the influence of neighbourhood-level factors on self-rated health indicate that deprivation, lower socio-economic status, poor-quality residential environment and transport, drug misuse, rubbish on the streets, unsafety, and dissatisfaction with green spaces are associated with fair to poor self-rated health $(3,17,26-30)$.

The mechanisms of the relation between contextual factors and poor self-rated health are not clear. Some authors suggest that neighbourhood problems may constitute a source of chronic stress, which may increase the risk of poor self-perception of health $(3,31)$. Documenting contextual factors that may contribute to modify such perception is important for the design and implementation of effective prevention strategies and interventions. It is important to better understand how group and individual factors interrelate in predicting self-rated individual health. In general, researchers in this field have not properly taken into account the role of individual and family influences while those focused on individual and family influences have generally disregarded the role of neighbourhood influences. Therefore, we need to develop conceptual frameworks incorporating various levels of analysis, as well as due consideration to potential mechanisms of relation as the lack of an appropriate theoretical framework may lead to deceptive conclusions. A common approach to such analysis is the multilevel design and its hierarchical model that allows the integration of independent variables from different levels of analysis (32-35).

There are relatively few studies in Latin America using an approach that simultaneously considers how individual and contextual aspects contribute to self-rated health status $(1,16,36)$ and even more scarce in Colombia, especially in Bogotá, which is considered one of Latin America's largest metropolitan areas. Understanding these associations is relevant in the light of the current Colombian ten-year public health plan and the Sustainable Development Goals for a healthy life and well-being for all (SDG 3), and inclusive, safe, resilient, and sustainable cities and human settlements (SDG 11). Consequently, this study aimed at examining the relationships 
between poor self-rated health and individual, family, and locality factors among Colombian adults living in Bogotá especially focused on the effects of locality structural and social conditions based on a conceptual model linking locality characteristics and poor self-rated health and on a multilevel model to evaluate the effect of locality conditions in adults' poor self-rated health and the interaction between individual and family factors. To our knowledge, this is the first study that explores contextual effects and self-rated health among adults in a Colombian urban context.

\section{Materials and methods}

\section{Design and study population}

Bogotá is the capital city of Colombia with a population of 7,467,000 inhabitants of whom $99 \%$ live in the urban area. The city is divided geographically and administratively into 20 localities. For the analysis, we used data from the multipurpose survey carried out in Bogotá in 2011 by the Departamento Administrativo Nacional de Estadística, DANE (37). The survey is a population-based study that collects information on the social, economic, and general living conditions of the population in Bogotá's 19 localities (excluding the semi-rural area of Sumapaz).

We used a probabilistic clustered sample stratified by socioeconomic status where the observational units were the households and noninstitutionalized individuals. The parameters for sample estimation were $5 \%$ relative standard error, $95 \%$ confidence level, and $10 \%$ prevalence of the main health indicators. The detailed account of the methods used for this population survey is available $(37,38)$. We used a cross-sectional design including 20-year-old and older individuals who completed the interview and provided information on their self-rated health. These data respond to a natural hierarchy structure with 37,352 individuals nested within 15,788 households from 19 urban localities.

\section{Study variables}

We used a questionnaire to collect a wide range of demographic and socio-economic information about individual and household conditions. Selfrated health was classified on a 1 to 4 scale: 'Very good,' 'good,' 'poor', and 'very poor'. Previous studies have suggested that self-rated health is a reliable indicator of an individual's current health with high predictive validity (39). To compare the results with those from other studies the original categories were recorded into a binary outcome: 0 for very good and good, and 1 for poor or very poor.

The following individual characteristics were also taken from the questionnaire and included in the analysis as independent variables: gender (male, female), age (20-29, 30-39, 40-49, 50-59, $\geq 60)$, schooling ( $\leq 5,6-11$, $>11$ years), marital status (with or without a partner), working mainly in the last week (yes/no), regular physical activity (yes/no), and morbidities (none, onetwo, or three or more of the following morbidities: cardiovascular diseases, respiratory diseases, kidney diseases, digestive diseases, arthritis, diabetes, malign tumours, mental diseases, or asthma/allergies). At the household level, we explored the effect of socio-economic status (low, middle, high), living in a noisy area (yes/no), contamination problems in the area (yes/no), insecurity (yes/no), close to rubbish dumps (yes/no), close to factories (yes/no), and presence of illicit drug markets (yes/no). 
Data on the socio-economic characteristics of the locality were taken from official national datasets reported by DANE $(37,40)$. At the locality level, we included:

1) quartiles of the Gini coefficient to measure the level of income inequality in the localities (values between 0 and 1) where the lowest quintile represents more equal localities and the highest one more unequal localities;

2) quartiles of poverty measuring the proportion of residents with disadvantageous life conditions regarding schooling, employment, access to health services, and housing where localities were categorized into quintiles, with the lowest quintile comprising the richest group of localities and the highest one the poorest localities (40);

3) homicide rate (per 100,000 inhabitants);

4) the percentage of population perceiving increased insecurity in their locality, and

5) population density defined as the number of residents per square meter $\left(\mathrm{m}^{2}\right)$.

\section{Conceptual model}

The analysis was based on a hierarchical conceptual model that not only considered a proposed hierarchy of causal relationships but also used criteria for selecting variables beyond purely statistical considerations (41). At the individual level, the most distal determinants were age and gender, schooling, marital status, and work-related status. The second level included the effects of being physically active and morbidities. At the household level, we included the effects of socio-economic status and location characteristics (living close to a noisy area with pollution problems, insecurity, and exposure to rubbish dumps, close to factories, and to illicit drug markets. Finally, at the locality level, we examined the distal effect of social conditions (Gini coefficient and poverty) which in their turn may have had a direct influence on the variables at the second level, the effects of the homicide rate, percentage of population perceiving an increase in insecurity in their locality, and population density.

Analytical procedures: Hierarchical analysis with a multilevel logistic model.

Estimates of poor self-rated health associated with individual, household, and locality characteristics and their respective 95\% confidence intervals were obtained by fitting a logistic regression model with random intercept, fixed coefficients, and a three-level structure with individuals at level 1 , households at level 2, and localities at level 3:

$$
\begin{array}{lllllll}
y_{i j k} & \beta_{0} & \beta_{1} x_{i j k} & \beta_{2} x_{j k} & \beta_{3} x_{k} & u_{0 j k} & v_{0 k}
\end{array}
$$

where is the poor self-rated health condition for individual $i$ in household $j$ within locality $k$. The log-probability of poor self-rated health for all individuals in all localities is represented by . The individual, household, and locality variables are represented by, and their regression coefficients by , respectively. These were transformed into odds ratios to facilitate comparisons. Finally, the household- and locality-level random effects are represented by and and they measure household and locality differences conditioned to the variables that are specified in the model. We assumed a normal distribution with the respective variances: expressed on a logit scale.

The level 1 unexplained variance, , assumes a Bernoulli distribution given the binary nature of the response. To indicate the percentage of variance due to differences among localities, the intra-class correlation coefficient 
was estimated using the ratio of the locality-level variance and the total variance. Moreover, to better quantify the effects of locality and understand their size, the locality-level variance was transformed to a median odds ratio (MOR) (42) by translating the locality-level variance into an odds ratio that quantified the variation among localities randomly choosing and comparing any two individuals from two different localities. This may be interpreted as the increased risk of poor self-rated health that an individual would have on average if he or she moved to another locality with a higher risk of poor health (43), which was estimated as:

$$
M O R=\exp \left(0,95 \sqrt{\left(2 * \sigma_{v 0}^{2}\right)} * 0,6745\right.
$$

where 0.6745 is the $75^{\text {th }}$ percentile of the cumulative distribution function of the standard normal distribution. The uncertainty interval of the MOR (Bayesian confidence intervals) was derived from the monitoring chain of the MCMC estimates and the above equations (44).

In the hierarchical conceptual model, the analysis consisted of a sequence of six models of growing complexity. The first model was a null model or model without covariates. The second one included the effect of the most distal determinants at individual level (age and gender, schooling, marital status, and work-related status). The third model included the effects of being physically active and morbidities. The fourth one explored the effect of household conditions (socio-economic status, location, and characteristics). Finally, in the last model, we examined the effect of the Gini coefficient and poverty, as well as the effect of the percentage of population perceiving an increase in insecurity of the locality and population density.

We used chi-squared tests with a significance level of $20 \%$ to identify potential confounders. This pre-specified cut-off value has proven to better identify the presence of confounding effects than using a cut-off of 0.05 $(45,46)$. We also used a chi-squared test for heterogeneity to analyze nominal variables. For ordinal variables, such as the neighbourhood variables, for which we hypothesized dose-response effects, we used a linear trend test.

Given that the urban localities to characterize differences and estimate the effect of some associated factors were only 19 , models were estimated with full Bayesian procedures to estimate exactly the parameters (44).

To validate the results of the random-effects model, the multilevel logistic model was re-specified as a fixed-effects model and the DIC index was used to choose between the fixed and random effects approach where the model with the lower DIC was preferred as a trade-off between complexity and fitness (47). Both methods gave similar point estimates, but the DIC index indicated better performance for the multilevel method (data not shown). The results we are presenting corresponded to the multilevel regression analysis.

The analyses were done with the MLwiN v2.31 statistical software package using the runmlwin command (48) with full Bayesian MCMC methods and minimally informative priors. Following Draper's (49) good-practice recommendations, a burn-in of 500 iterations was used with monitoring for another 50,000 iterations.

The analyses were based on publicly available data from a national survey and official national datasets. Ethics procedures were the responsibility of the institutions that commissioned, funded, or administered the surveys/data collection. 


\section{Results}

Table 1 describes individuals, households, and locality characteristics. More than half of the respondents were women, $48 \%$ were aged 20 to 39 years old, a third had more than 11 years of schooling, two thirds had a partner, and $67 \%$ reported having a job during the previous week. Regarding their health conditions, around a fifth of the individuals reported being physically active and $60 \%$ reported not suffering from morbidities. Most of the households were located in middle- and low-socioeconomic status areas. A third of them were located in areas with noise, contamination, and insecurity problems, close to rubbish dumps, industries, and illicit drug markets. On average, localities had a population density of 181 inhabitants $/ \mathrm{m}^{2}$, a homicide rate of 42 homicides per 100,000 inhabitants, $45 \%$ of their residents perceived an increase in insecurity, the Gini coefficient at the lowest inequality quartile was 0.39 while at the highest it was 0.55 . At least $22 \%$ of the population in the poorer localities lived in poverty.

The prevalence of poor self-rated health in the population was $24 \%(95 \%$ confidence intervals: $21 \%-26 \%$ ). We found strong evidence of variation on the prevalence of poor self-rated health among localities $(p<0.001)$. Figure 1 shows the scale of the differences plotting the distribution of localities according to the intervals of the prevalence of poor self-rated health predicted from the null model by means of the simulation-based procedures of the MLwiN customized predictions (50). The differential prevalence showed that individuals in northern Bogota had better self-rated health than those from southern Bogota.

The locality-level variance of 0.09 translated into a $1.31 \mathrm{MOR}(95 \% \mathrm{Cl}$ : 1.16-1.42), which suggests significant differences between localities. For instance, if an individual were to move from a locality with a low prevalence of poor self-rated health to one with high prevalence, his or her individual odds were around $31 \%$ greater than if he or she stayed in a lower risk locality.

Table 2 shows the prevalence of poor self-rated health by independent variables. The crude analysis showed that individuals older than 60 years had around $65 \%$ higher odds of having poor self-rated health compared to those aged 20-29 years. Having less than five years of education increased five times the odds of poor self-rated health compared to those with 11 years or more. Similarly, women, people without a partner and/or a job during the previous week, those physically inactive, and those suffering from three or more morbidities had much higher odds for poor self-rated health when compared to their reference categories. Additionally, people living in households from low socio-economic status noisy areas, with contamination and insecurity problems, close to rubbish dumps, factories, and illicit drug markets showed greater odds for poor self-rated health when compared with their reference categories. Similarly, localities with low inequality, high poverty level, high rate of homicides, and high population density showed greater odds for poor self-rated health. The insecurity level of the localities was not associated with self-rated health.

Adjusted analyses were carried out according to the hierarchical levels described in the methods section. After adjustment, the odds of poor selfrated health for people older than 50 years remained higher when compared to those aged 20-19 years old. The association with the years of education, not having a partner and/or a job, being physically inactive, and suffering from three or more morbidities also remained significant. The association of residing in poor households in areas with noise, contamination, and security 
Table 1. Studied population according to individual, household, and locality characteristics, Bogotá, Colombia, 2011

\begin{tabular}{|c|c|c|}
\hline Variable & $\mathbf{n}$ & $\%$ \\
\hline \multicolumn{3}{|l|}{ Individual level $(n=37,352)$} \\
\hline \multicolumn{3}{|l|}{ Gender } \\
\hline Male & 16,846 & 45.10 \\
\hline $\begin{array}{l}\text { Female } \\
\text { Age }\end{array}$ & Age & 54.90 \\
\hline $20-29$ & 9,681 & 25.92 \\
\hline $30-39$ & 8,155 & 21.83 \\
\hline $40-49$ & 7,475 & 20.01 \\
\hline $50-59$ & 5,824 & 15.59 \\
\hline \multicolumn{3}{|l|}{ Schooling (years with passing scores) } \\
\hline$<=5$ & 10,575 & 29.13 \\
\hline $6-11$ & 13,644 & 37.58 \\
\hline$>11$ & 12,088 & 33.29 \\
\hline \multicolumn{3}{|l|}{ Marital status } \\
\hline With a partner & 24,53 & 65.67 \\
\hline Without a partner & 12,822 & 34.33 \\
\hline \multicolumn{3}{|l|}{ Working } \\
\hline Yes & 25,127 & 67.27 \\
\hline No & 12,225 & 32.73 \\
\hline \multicolumn{3}{|l|}{ Regular physical activity } \\
\hline Yes & 7,939 & 21.25 \\
\hline No & 29,413 & 78.75 \\
\hline \multicolumn{3}{|l|}{ Morbidities } \\
\hline 0 & 22,48 & 60.18 \\
\hline $1-2$ & 12,735 & 34.09 \\
\hline \multirow{2}{*}{\multicolumn{3}{|c|}{ Household level $(n=15,788)$}} \\
\hline & & \\
\hline \multicolumn{3}{|l|}{ Socio-economic status } \\
\hline Low & 6,829 & 43.30 \\
\hline Middle & 7,974 & 50.50 \\
\hline High & 780 & 4.90 \\
\hline \multicolumn{3}{|l|}{ Located within a noisy area } \\
\hline Yes & 6,269 & 39.70 \\
\hline No & 9,515 & 60.30 \\
\hline \multicolumn{3}{|l|}{ Located within an area with contamination problems } \\
\hline Yes & 7,517 & 47.60 \\
\hline No & 8,269 & 52.40 \\
\hline \multicolumn{3}{|l|}{ Located within an area with insecurity problems } \\
\hline Yes & 12,095 & 76.60 \\
\hline No & 3,696 & 23.40 \\
\hline \multicolumn{3}{|l|}{ Close to rubbish dump } \\
\hline Yes & 2,047 & 13.00 \\
\hline No & 13,741 & 87.00 \\
\hline \multicolumn{3}{|l|}{ Close to factories } \\
\hline Yes & 3,426 & 21.70 \\
\hline No & 12,362 & 78.30 \\
\hline \multicolumn{3}{|l|}{ Close to drug markets } \\
\hline Yes & 4,403 & 27.90 \\
\hline No & 11,385 & 72.10 \\
\hline Locality level $(n=19)$ & & \\
\hline Gini coefficient & & \\
\hline Quartile 1 & 5 & 0.39 \\
\hline Quartile 2 & 4 & 0.42 \\
\hline Quartile 3 & 5 & 0.48 \\
\hline Quartile 4 & 5 & 0.55 \\
\hline Population in poverty (\%) & & \\
\hline Quartile 1 & 6 & 5.61 \\
\hline Quartile 2 & 5 & 10.30 \\
\hline Quartile 3 & 4 & 16.00 \\
\hline Quartile 4 & 4 & 21.90 \\
\hline Mean (SD) homicide rate $\times 100,000$ & 42.35 & (36.35) \\
\hline $\begin{array}{l}\text { Mean (SD) of population perceiving an increase in the } \\
\text { insecurity }(\%)\end{array}$ & 45.0 & $5(7.65)$ \\
\hline Mean (SD) population density $\left(\mathrm{m}^{2}\right)$ & 180.72 & $(56.41)$ \\
\hline
\end{tabular}


Figure 1. Predicted prevalence of poor health by locality of residence, Bogotá-Colombia, 2011

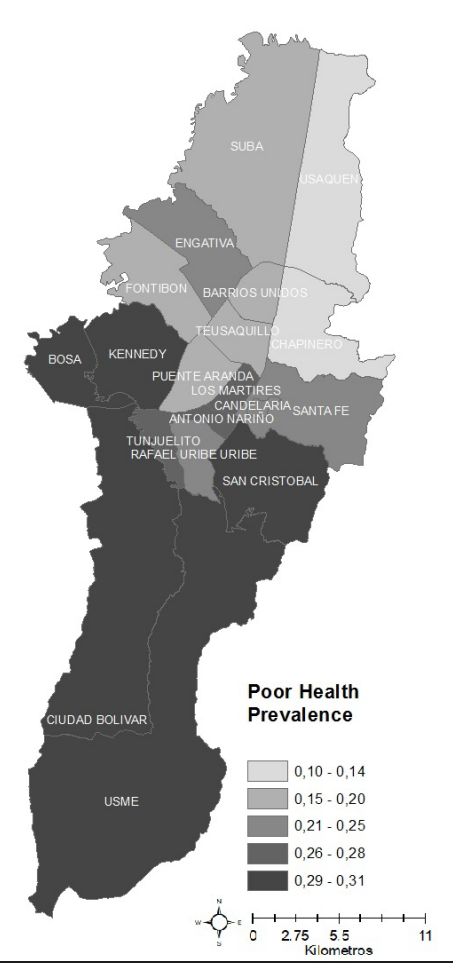

problems, close to factories and illicit drug markets was virtually unaltered by adjustment. We found a dose-response relationship between locality poverty and odds of poor self-rated health. Otherwise, the association of gender, household close to rubbish dumps, Gini coefficient, homicide, and population density with poor self-rated health disappeared after adjustment (table 2).

In the adjusted model, the between-locality variance decreased to 0.004 . This equates to a $1.06 \mathrm{MOR}(95 \% \mathrm{Cl}: 1.00 ; 1.11)$, which means that after considering the effects of individual, household, and locality characteristics there are no unexplained differences between localities. This result is also shown by the adjusted ICC of $0.048 \%$ in the final model.

\section{Discussion}

We examined the effect of context- and individual-related variables on poor self-rated health in Colombian adults living in a metropolitan area. Our results confirmed that the characteristics of individuals, households, and place of residence influenced individual health perception.

We found greater odds of poor self-rated health in individuals aged 50 years or older, those with lower education, without a partner and/or employment, non-physically-active individuals on a regular basis, and those who reported more than three morbidities. After adjusting for individual characteristics, household characteristics were also associated with poor self-rated health. Low socioeconomic households located in areas with problems of noise, pollution, neighbourhood insecurity, and near factories or illicit drug markets showed greater odds of poor self-rated health. Additionally, localities with a higher proportion of poverty showed greater odds of poor self-rated health independently from individual and household factors. These findings are consistent with other studies showing strong associations between physical conditions of the place of residence and individual health 
Table 2. Prevalence, crude, and adjusted analyses of the association between individual, household, and locality-related variables and poor or very poor health, Bogotá D.C., Colombia, 2011

\begin{tabular}{|c|c|c|c|c|c|}
\hline \multicolumn{4}{|c|}{ Crude analysis } & \multicolumn{2}{|c|}{ Adjusted analysis ${ }^{\star *}$} \\
\hline Variable & Prevalence & OR (Cl 95\%) & p-value & OR (Cl 95\%) & p-value \\
\hline \multicolumn{6}{|l|}{ Individual level } \\
\hline Gender & & & 0.002 & & 0.2 \\
\hline Male & 24.05 & Reference & & Reference & \\
\hline Female & 26.43 & $1.08(1.03 ; 1.14)$ & & $1.03(0.98 ; 1.09)$ & \\
\hline Age & & & $<0.001$ & & $<0.001^{\star}$ \\
\hline $20-29$ & 22.21 & Reference & & Reference & \\
\hline $30-39$ & 18.12 & $0.85(0.78 ; 0.93)$ & & $0.78(0.72 ; 0.85)$ & \\
\hline $40-49$ & 22.96 & $1.04(0.96 ; 1.13)$ & & $1.05(0.97 ; 1.13)$ & \\
\hline $50-59$ & 29.38 & $1.28(1.18 ; 1.40)$ & & $1.33(1.23 ; 1.44)$ & \\
\hline$\geq 60$ & 38.88 & $1.65(1.52 ; 1.80)$ & & $1.46(1.35 ; 1.59)$ & \\
\hline Schooling (years with passing scores) & & & $<0.001$ & & $<0.001^{*}$ \\
\hline$<=5$ & 43.35 & $4.89(4.38 ; 5.45)$ & & $3.75(3.49 ; 4.03)$ & \\
\hline $6-11$ & 23.36 & $1.95(1.76 ; 2.16)$ & & $1.87(1.74 ; 2.01)$ & \\
\hline$>11$ & 13.33 & Reference & & Reference & \\
\hline Marital status & & & $<0.001$ & & $<0.001$ \\
\hline With a partner & 22.48 & Reference & & Reference & \\
\hline Without a partner & 30.87 & $1.62(1.49 ; 1.75)$ & & $1.27(1.20 ; 1.34)$ & \\
\hline Working & & & $<0.001$ & & $<0.001$ \\
\hline Yes & 17.99 & Reference & & Reference & \\
\hline No & 40.51 & $3.19(2.94 ; 3.46)$ & & $2.38(2.25 ; 2.51)$ & \\
\hline Regular physical activity & & & $<0.001$ & & $<0.001$ \\
\hline Yes & 21.15 & Reference & & Reference & \\
\hline No & 26.5 & $1.25(1.14 ; 1.37)$ & & $1.41(1.32 ; 1.51)$ & \\
\hline Morbidities & & & $<0.001$ & & $<0.001^{\star}$ \\
\hline 0 & 11.46 & Reference & & Reference & \\
\hline $1-2$ & 41.85 & $5.65(5.16 ; 6.19)$ & & $5.00(4.72 ; 5.31)$ & \\
\hline$>=3$ & 73.33 & $22.93(19.11 ; 27.51)$ & & $17.02(15.17 ; 19.08$ & \\
\hline \multicolumn{6}{|l|}{ Household level } \\
\hline Socio-economic status & & & $<0.001$ & & $<0.001^{*}$ \\
\hline Low & 30.03 & $2.90(2.28 ; 3.70)$ & & $2.21(1.78 ; 2.74)$ & \\
\hline Middle & 22.67 & $2.05(1.62 ; 2.59)$ & & $1.75(1.42 ; 2.14)$ & \\
\hline High & 8.71 & Reference & & Reference & \\
\hline Located within a noisy area & & & $<0.001$ & & $<0.001$ \\
\hline Yes & 28.53 & $1.32(1.22 ; 1.43)$ & & $1.12(1.06 ; 1.19)$ & \\
\hline No & 23.27 & Reference & & Reference & \\
\hline Located within an area with contamination problems & & & $<0.001$ & & $<0.001$ \\
\hline Yes & 27.95 & $1.29(1.20 ; 1.40)$ & & $1.15(1.08 ; 1.22)$ & \\
\hline No & 23.00 & Reference & & Reference & \\
\hline Located within an area with insecurity problems & & & $<0.001$ & & $<0.001$ \\
\hline Yes & 27.47 & $1.53(1.39 ; 1.69)$ & & $1.20(1.12 ; 1.30)$ & \\
\hline No & 17.98 & Reference & & Reference & \\
\hline Close to rubbish dumps & & & $<0.001$ & & 0,889 \\
\hline Yes & 31.57 & $1.31(1.17 ; 1.47)$ & & $1.01(0.93 ; 1.09)$ & \\
\hline No & 24.42 & Reference & & Reference & \\
\hline Close to factories & & & 0.01 & & $<0,001$ \\
\hline Yes & 27.81 & $1.53(1.39 ; 1.69)$ & & $1.14(1.06 ; 1.22)$ & \\
\hline No & 24.65 & Reference & & Reference & \\
\hline Close to drug markets & & & $<0.001$ & & $<0,001$ \\
\hline Yes & 30.87 & $1.53(1.39 ; 1.69)$ & & $1.18(1.11 ; 1.26)$ & \\
\hline No & 23.24 & Reference & & Reference & \\
\hline \multicolumn{6}{|l|}{ Locality level } \\
\hline Gini coefficient & & & 0.004 & & $0,588^{*}$ \\
\hline Quartile 1 & 29.72 & $1.73(1.26 ; 2.39)$ & & $1.27(0.97 ; 1.65)$ & \\
\hline Quartile 2 & 25.05 & $1.36(0.96 ; 1.91)$ & & $1.08(0.93 ; 1.27)$ & \\
\hline Quartile 3 & 25.33 & $1.39(1.00 ; 1.91)$ & & $1.09(0.94 ; 1.28)$ & \\
\hline Quartile 4 & 19.79 & Reference & & Reference & \\
\hline Population in poverty (\%) & & & $<0.001$ & & $0.003^{*}$ \\
\hline Quartile 1 & 18.84 & Reference & & Reference & \\
\hline Quartile 2 & 25.54 & $1.50(1.18 ; 1.92)$ & & $1.31(1.12 ; 1.52)$ & \\
\hline Quartile 3 & 27.64 & $1.68(1.30 ; 2.18)$ & & $1.25(1.06 ; 1.47)$ & \\
\hline Quartile 4 & 30.61 & $1.96(1.51 ; 2.53)$ & & $1.36(1.15 ; 1.61)$ & \\
\hline Mean (SD) homicide rate $\times 100,000$ & & $1.00(1.00 ; 1.01)$ & 0.04 & $1.00(0.99 ; 1.00)$ & 0.476 \\
\hline Mean (SD) of population perceiving an increase in the & insecurity (\%) & $1.01(0.98 ; 1.02)$ & 0.57 & $0.99(0.97 ; 1.01)$ & 0.771 \\
\hline Mean (SD) population density $\left(\mathrm{m}^{2}\right)$ & & $1.00(1.00 ; 1.01)$ & 0.01 & $0.99(0.96 ; 1.00)$ & 0.570 \\
\hline
\end{tabular}


$(3,16,17,21,32,51)$. In general, poorer areas usually present characteristics that are unfavourable to good health such as inadequate healthcare networks, absence of areas for practicing physical activities, a poorly organized physical environment (accumulated garbage, dirtiness, pollution, noise, overcrowding), deficient basic sanitation, transportation, and education, insufficient levels of social cohesion and participation, and greater exposure to violence (16$18,23,32,51)$.

The main methodological limitation of studies that investigate contextrelated characteristics is the definition of the geographic area whose characteristics may be relevant to the specific health outcome under study (18). As we were interested in analyzing the association of the physical environment and the structural characteristics of the place of residence with self-perceived health, the geographically administrative definition of localities was relevant to us as we think it validates the individual perception of these areas to a certain extent given that the localities are previously defined political and administrative units and, therefore, a natural grouping for the respondents. The greatest advantage of using this geographical unit in the analysis is the feasibility of obtaining variables measured at that level. The main disadvantage is that such grouping may not reflect the true context in which individuals are exposed to contextual risks. An additional limitation concerns the study design. Studies with a cross-sectional design are limited to identifying associations rather than causal relationships and reverse causality may exist, especially at individual-level variables. For instance, it can be argued that individuals reported poorer health because they were unemployed or that they were unemployed because of their poor health. Thus, longitudinal studies are important to confirm the associations reported here. Furthermore, we cannot rule out the possibility of residual confounding factors that were not explored, such as individual income or wealth, and of lack of precision in certain measurements of socioeconomic characteristics, such as education and employment status.

Stratified analyses exploring sex differences may have been important in previous studies as they showed that self-reported health and the use of health services was worse in women than in men $(16,52)$. Those findings are important as they suggest that women might benefit more from better health services or suffer more due to a lack of them in a wealthy or poor area, respectively. However, we did not find differences by sex in our results (data available on request). Additional analyses exploring conflicting findings among studies regarding sex differences are needed.

To understand the multifaceted nature of poor self-perceived health, multilevel conceptual models are needed to explain the interaction of risk factors at different levels. This study implemented an integrated theoretical framework combining individual and contextual theories on poor health, arranging variables on logical temporal order, guiding the adjusted analysis, and, consequently, improving the estimations of the effects of locality-, family-, and individual-related characteristics of poor health self-perception. Our study showed an association between context-related variables and self-rated health status in a Colombian urban population. Further studies will be required to confirm these associations in different populations (rural, from other Colombian geographical regions or Latin American metropolitan areas), study designs, and health-related outcomes. These findings suggest that health policies and interventions aimed at improving people's health and quality of life should include integral and multisector initiatives according 
to specific needs per area. Area-based strategies should take into account concerted approaches ensuring a focus on context-related variables rather than on individual-level strategies alone. Implementing these area-based strategies in Colombia might help towards the achievement of the SDGs and the Colombian Public Health Plan. To date, no study in Colombia has simultaneously considered the effect of locality, family, and individual factors on adult health perception and such approach has been scarcely used in lowand middle-income countries. Therefore, we hope our paper will contribute to the understanding of these associations in an urban area in Colombia in favour of policy-making and interventions to improve the health and well-being of individuals living in urban environments.

\section{References}

1. Alazraqui M, Diez Roux A V, Fleischer N, Spinelli H. Self-rated health and social inequalities, Buenos Aires, Argentina, 2005. Cad Saúde Pública. 2009;25:1990-2000. https://doi.org/10.1590/S0102-311X2009000900013

2. Velarde-Jurado E, Avila-Figueroa C. Evaluation of the quality of life. Salud Pública Mex. 2002;44:349-61.

3. Agyemang C, van Hooijdonk C, Wendel-Vos W, Lindeman E, Stronks K, Droomers M. The association of neighbourhood psychosocial stressors and self-rated health in Amsterdam, The Netherlands. J Epidemiol Community Health. 2007;61:1042-9. ttps://doi.org/10.1136/jech.2006.052548

4. Heistaro S, Jousilahti P, Lahelma E, Vartiainen E, Puska P. Self-rated health and mortality: A long term prospective study in eastern Finland. J Epidemiol Community Health. 2001;55:22732. https://doi.org/10.1136/jech.55.4.227

5. Idler EL, Angel RJ. Self-rated health and mortality in the NHANES-I Epidemiologic Follow-up Study. Am J Public Heal. 1990;80:446-52. https://doi.org/10.2105/AJPH.80.4.446

6. Idler EL, Benyamini Y. Self-rated health and mortality: A review of twenty-seven community studies. J Health Soc Behav. 1997;38:21-37.

7. Idler EL, KasI S V, Lemke JH. Self-evaluated health and mortality among the elderly in New Haven, Connecticut, and lowa and Washington counties, lowa, 1982-1986. Am J Epidemiol. 1990;131:91-103. https://doi.org/10.1093/oxfordjournals.aje.a115489

8. Mossey JM, Shapiro E. Self-rated health: A predictor of mortality among the elderly. Am J Public Health. 1982;72:800-8. https://doi.org/10.2105/AJPH.72.8.800

9. Benavides FG, Benach J, Diez-Roux A V, Roman C. How do types of employment relate to health indicators? Findings from the second European survey on working conditions. J Epidemiol Community Health. 2000;54:494-501. https://doi.org/10.1136/jech.54.7.494

10. Benyamini $\mathrm{Y}$, Leventhal $E A$, Leventhal $\mathrm{H}$. Gender differences in processing information for making self-assessments of health. Psychosom Med. 2000;62:354-64.

11. Dachs JN. Factors determining inequalities in the health condition self-assessment in Brazil: Analysis of data of PNAD/1998. Cien Saúde Colet. 2002;7:641-57.

12. Heistaro S, Laatikainen T, Vartiainen E, Puska P, Uutela A, Pokusajeva S, et al. Self-reported health in the Republic of Karelia, Russia and in north Karelia, Finland in 1992. Eur J Public Health. 2001;11:74-80. https://doi.org/10.1093/eurpub/11.1.74

13. Mansyur C, Amick BC, Harrist RB, Franzini L. Social capital, income inequality, and selfrated health in 45 countries. Soc Sci Med. 2008;66:43-56. https://doi.org/10.1016/j.socscimed.2007.08.015

14. Kawachi I, Subramanian SV. Neighbourhood influences on health. J Epidemiol Community Health. 2007;61:3-4. https://doi.org/10.1136/jech.2005.045203

15. Macintyre S, Ellaway A, Cummins S. Place effects on health: How can we conceptualise, operationalise and measure them? Soc Sci Med. 2002;55:125-39.

16. Cremonese C, Backes V, Olinto MT, Dias-da-Costa JS, Pattussi MP. Neighborhood sociodemographic and environmental contexts and self-rated health among Brazilian adults: A multilevel study. Cad Saúde Pública. 2010;26:2368-78. https://doi.org/10.1590/S0102-311X2010001200015 
17. Cummins S, Stafford M, Macintyre S, Marmot M, Ellaway A. Neighbourhood environment and its association with self rated health: Evidence from Scotland and England. J Epidemiol Community Health. 2005;59:207-13. https://doi.org/10.1136/jech.2003.016147

18. Diez Roux AV, Am JP. Investigating neighborhood and area effects on health. Am J Public Health. 2001;91:1783-9. https://doi.org/10.2105/ajph.91.11.1783

19. Diez Roux AV. Neighborhoods and health: Where are we and where do we go from here? Rev Epidemiol Santé Publique. 2007;55:13-21.

20. 20. Pampalon R, Hamel D, De Koninck M, Disant MJ. Perception of place and health: Differences between neighbourhoods in the Quebec City region. Soc Sci Med. 2007;65:95111. https://doi.org/10.1016/j.socscimed.2007.02.044

21. Patel K V, Eschbach K, Rudkin LL, Peek MK, Markides KS. Neighborhood context and selfrated health in older Mexican Americans. Ann Epidemiol. 2003;13:620-8. https://doi.org/10.1016/S1047-2797(03)00060-7

22. Poortinga W, Dunstan FD, Fone DL. Neighbourhood deprivation and self-rated health: The role of perceptions of the neighbourhood and of housing problems. Health Place. 2008;14:562-75. https://doi.org/10.1016/j. healthplace.2007.10.003

23. Poortinga W, Dunstan FD, Fone DL. Perceptions of the neighbourhood environment and self rated health: A multilevel analysis of the Caerphilly Health and Social Needs Study. BMC Public Health. 2007;7:285. https://doi.org/10.1186/1471-2458-7-285

24. Mrug S, Windle M. Mediators of neighborhood influences on externalizing behavior in preadolescent children. J Abnorm Child Psychol. 2009;37:265-80. https://doi.org/10.1007/s10802-008-9274-0

25. Sampson RJ, Raudenbush SW, Earls F. Neighborhoods and violent crime: A multilevel study of collective efficacy. Science. 1997;277:918-24. https://doi.org/10.1126/science.277.5328.918

26. Reijneveld SA, Verheij RA, De Bakker DH. The impact of area deprivation on differences in health: Does the choice of the geographical classification matter? J Epidemiol Community Health. 2000;54:306-13. https://doi.org/10.1136/jech.54.4.306

27. Reijneveld SA. Neighbourhood socioeconomic context and self reported health and smoking: A secondary analysis of data on seven cities. J Epidemiol Community Health. 2002;56:93542. https://doi.org/10.1136/jech.56.12.935

28. Wen M, Browning CR, Cagney KA. Poverty, affluence, and income inequality: Neighborhood economic structure and its implications for health. Soc Sci Med. 2003;57:843-60. https://doi. org/10.1016/S0277-9536(02)00457-4

29. 29. Franzini L, Caughy M, Spears W, Fernández-Esquer ME. Neighborhood economic conditions, social processes, and self-rated health in low-income neighborhoods in Texas: A multilevel latent variables model. Soc Sci Med. 2005;61:1135-50. https://doi.org/10.1016/j.socscimed.2005.02.010

30. Stafford M, Marmot M. Neighbourhood deprivation and health: Does it affect us all equally? Int J Epidemiol. 2003;32:357-66. https://doi.org/10.1093/ije/dyg084

31. Steptoe A, Feldman PJ. Neighborhood problems as sources of chronic stress: Development of a measure of neighborhood problems, and associations with socioeconomic status and health. Ann Behav Med. 2001;23:177-85. https://doi.org/10.1207/S15324796ABM2303 5

32. Wong IO, Cowling BJ, Lo S V, Leung GM. A multilevel analysis of the effects of neighbourhood income inequality on individual self-rated health in Hong Kong. Soc Sci Med. 2009;68:124-32. https://doi.org/10.1016/i.socscimed.2008.09.064

33. Diez Roux AV. A glossary for multilevel analysis. J Epidemiol Community Health. 2002;56:588-94. https://doi.org/10.1136/jech.56.8.588

34. Diez-Roux AV. Multilevel analysis in public health research. Annu Rev Public Health. 2000;21:171-92. https://doi.org/10.1146/annurev.publhealth.21.1.171

35. Duncan C, Jones K, Moon G. Context, composition and heterogeneity: Using multilevel models in health research. Soc Sci Med. 1998;46:97-117. https://doi.org/10.1016/S0277-9536(97)00148-2

36. Santos SM, Chor D, Werneck GL, Coutinho ES. Association between contextual factors and self-rated health: A systematic review of multilevel studies. Cad Saúde Pública. 2007;23:2533-54. https://doi.org/10.1590/S0102-311X200700110000 
37. Departamento Administrativo Nacional de Estadística. Encuesta Multipropósito para Bogotá Distrito Capital: EMB 2011 Información general. Accessed: March 13, 2018. Available from: http://microdatos.dane.gov.co/index.php/catalog/189/related materials

38. Alcaldía Mayor Santa Fé de Bogotá. Encuesta Multipropósito para Bogotá EMB 20112014. Accessed: March 13, 2018. Available from: http://www.sdp.gov.co/sites/default/files/ presentacion 03 febre 2016.pdf

39. Diez-Roux AV, Link BG, Northridge ME. A multilevel analysis of income inequality and cardiovascular disease risk factors. Soc Sci Med. 2000;50:673-87. https://doi.org/10.1016/S0277-9536(99)00320-2

40. Alcaldía Mayor Santa Fé de Bogotá. Indicadores de pobreza. Encuesta multipropósito. Bogotá D.C.: Alcaldía Mayor; 2011.

41. Victora CG, Huttly SR, Fuchs SC, Olinto MT. The role of conceptual frameworks in epidemiological analysis: A hierarchical approach. Int J Epidemiol. 1997;26:224-7. https://doi.org/10.1093/ije/26.1.224

42. Merlo J, Chaix B, Ohlsson H, Beckman A, Johnell K, Hjerpe P, et al. A brief conceptual tutorial of multilevel analysis in social epidemiology: Using measures of clustering in multilevel logistic regression to investigate contextual phenomena. J Epidemiol Community Health. 2006;60:290-7. https://doi.org/10.1136/jech.2004.029454

43. Larsen K, Merlo J. Appropriate assessment of neighborhood effects on individual health: Integrating random and fixed effects in multilevel logistic regression. Am J Epidemiol. 2005;161:81-8. https://doi.org/10.1093/aje/kwi017

44. Jones K, Subramanian S. Developing multilevel models for analysing contextuality, heterogeneity and change. Volume 1. Boston MA: University of Bristol; 2013.

45. Mickey RM, Greenland S. The impact of confounder selection criteria on effect estimation. Am J Epidemiol. 1989;129:125-37. https://doi.org/10.1093/oxfordjournals.aje.a115101

46. Maldonado G, Greenland S. Simulation study of confounder-selection strategies. Am J Epidemiol. 1993;138:923-36. https://doi.org/10.1093/oxfordjournals.aje.a116813

47. Spiegelhalter DJ, Best NG, Carlin BP, Van Der Linde A. Bayesian measures of model complexity and fit. J R Stat Soc Ser B Stat Methodol. 2002;64:583-639.

48. Leckie G, Charlton C. runmlwin : A Program to Run the MLwiN Multilevel Modeling Software from within Stata. J Stat Softw. 2015;52:1-40.

49. Draper D. Bayesian Multilevel Analysis and MCMC. In: Leeuw J., Meijer E, editors. Handbook of Multilevel Analysis. New York, NY: Springer: 2008.

50. Rasbash J, Steele F, Browne WJ, Goldstein H, Charlton CMJ. A User 's Guide to MLwiN, v2.26. Centre for Multilevel Modelling. Bristol: University of Bristol; 2012.

51. Tay JB, Kelleher CC, Hope A, Barry M, Gabhainn SN, Sixsmith J. Influence of sociodemographic and neighbourhood factors on self-rated health and quality of life in rural communities: Findings from the agriproject in the Republic of Ireland. J Epidemiol Community Health. 2004;58:904-11. https://doi.org/10.1136/jech.2002.006643

52. Stafford M, Cummins S, Macintyre S, Ellaway A, Marmot M. Gender differences in the associations between health and neighbourhood environment. Soc Sci Med. 2005;60:168192. https://doi.org/10.1016/i.socscimed.2004.08.028 